\title{
Role of Magnesium Sulphate in Attenuating Succinylcholine Induced Fasiculations and Post-Operative Myalgia
}

\author{
Rukhsana Najeeb $^{1}$, Sylph Tajamul ${ }^{2 *}$, Arshid Ahmad Sofi ${ }^{3}$
}

${ }^{1}$ Professor \& Head of Department, Department of Anesthesiology \& Critical Care, Govt. Medical College, Srinagar, India

${ }^{2}$ Post Graduate scholar, Department of Anesthesiology \& Critical Care, Govt. Medical College, Srinagar, India

${ }^{3}$ Senior Resident, Department of Anesthesiology \& Critical Care, Govt. Medical College, Srinagar, India

\author{
DOI: 10.36348 /SJMPS.2019.v05i10.012 $\quad$ | Received: 21.10 .2019 | Accepted: 28.10 .2019 | Published: 30.10 .2019 \\ *Corresponding author: Dr. Sylph Tajamul
}

Abstract

Objectives: To measure the degree of attenuation of fasciculations and the degree of reduction in post-operative myalgia caused by Succinylcholine in patients pretreated with Magnesium Sulphate during the induction of general anaesthesia. Methods: This observational study was conducted from June 2016 to June 2019 in the Department of Anesthesiology in Government Medical College Srinagar, on patients who were candidates for surgery under general anaesthesia. Patients were selected and divided into two equal groups of cases and controls using block randomization. The cases received magnesium sulphate, while the controls received normal saline. SPSS 18 was used for statistical analysis. Results: Of the 100 subjects in the study, $57(57 \%)$ were men and $43(43 \%)$ were women $(\mathrm{p}=1.0)$. The mean age of the two groups were $35.55 \pm 13.56$ years and $32.80 \pm 13.37$ years $(\mathrm{p}=0.85)$. The incidence of fasciculations was $06(12 \%)$ patients in group $\mathrm{M}$ and 43(86\%) patients in group S. The incidence of fasciculations between two groups was highly significant $(\mathrm{p}=0.001)$. Postoperative myalgia was present in $9(18 \%)$ patients of Group $\mathrm{M}$ and $38(76 \%)$ patients in Group S experienced myalgia in postoperative period. The results were highly significant between two groups $(p=0.001)$. Conclusions: Magnesium sulphate can prevent and reduce the degree of fasciculation and postoperative myalgia after anaesthesia. Therefore it can be used to prevent fasciculation and postoperative myalgia

Keywords: Magnesium sulphate, Muscle fasciculation, Succinylcholine, postoperative myalgia.

Copyright @ 2019: This is an open-access article distributed under the terms of the Creative Commons Attribution license which permits unrestricted use, distribution, and reproduction in any medium for non-commercial use (NonCommercial, or CC-BY-NC) provided the original author and source are credited.

\section{INTRODUCTION}

Anaesthesia is a state of temporary, induced, loss of sensation or awareness to allow surgical procedures that would otherwise be intolerably painful to the patient. Muscle relaxation allows surgery within major body cavities such as the abdomen and thorax, and also facilitates endotracheal intubation [1].

Succinylcholine is considered by many clinicians, to be the best drug for providing ideal intubating conditions for surgical procedures, anticipated difficult airways and rapid sequence induction and intubation due to its fast onset of action, profound neuromuscular blockade and an ultra-short duration of action. Because of these qualities many clinicians believe it is still a good choice for routine intubation in adults. Succinylcholine is a relatively safe drug; however, in addition to a number of infrequent, but well known, untoward effects, its usefulness is limited by the frequent occurrence of postoperative myalgia. The first visible effect of injection of Succinylcholine was diffuse uncoordinated contractions of muscle bundles and groups. The occasional vigour of these contractions may give rise to a feeling of muscular stiffness after consciousness has been regained [2]. The first attempt to reduce the incidence and severity of muscle pain was pretreatment with Gallamine in 1954[3]. Since then, a wide variety of regimens has been tried. The reported incidence of Succinylcholine induced myalgia ranges from 1.5 to $89 \%[4,5]$.

Postoperative muscle damages and myalgia are attributed to different mechanisms including increased myoplasmic calcium concentration, changes in membrane phospholipids, releasing free fatty acids and the involvement of free radicals [6, 7]. Therefore, various methods and drugs have been suggested for the prevention of these complications. Magnesium Sulphate is one of the drugs that has recently been investigated largely [8, 9]. Magnesium acts as an adrenergic antagonist and inhibits the release of catecholamine. So it probably controls the undesirable effects of laryngoscopy for tracheal intubation such as 
tachycardia, hypertension, and increased intraocular pressure [10,11]. On the other hand, Magnesium Sulphate reduces the negative effects caused by Succinylcholine and avoids the increase of potassium concentration after administration of Succinylcholine. Furthermore, using Magnesium Sulphate before tracheal intubation relieves the haemodynamic response $[12,13]$. Magnesium Sulphate is also effective in reducing pain after the administration of succinylcholine [14]. Nevertheless, there are few studies investigating this drug. Therefore, this study is planned to assess the effects of Magnesium Sulphate on muscle fasciculation and post-operative myalgia caused by Succinylcholine in patients during the induction of anaesthesia.

\section{METHODS}

The present study was conducted in the Department of Anesthesiology in Government Medical College Srinagar from June 2016 to June 2019 on One hundred patients of (ASA) physical status I-II of both sexes, aged between 18 to 60 years, equally divided in to two groups, Group $\mathrm{S} \quad(\mathrm{n}=50)$, and Group $\mathrm{M}$ $(n=50)$.Patients undergoing elective surgery under general anaesthesia were included in this observational study. Patient who were allergic to study drugs, pregnant women, patients undergoing emergency surgeries, patients having history of muscular disease, malignant hyperthermia or suffering from hypotension, hypoparathyroidism and hypocalcaemia were excluded from this study.

After getting approval from Institutional Ethical Committee, written informed consent was obtained from all the patients before surgery. All patients were transported to the operating room without premedication. On arrival to operating room, an 18 gauge intravenous (IV) catheter was inserted, connected to multichannel monitor, monitoring of electrocardiography, non-invasive blood pressure, oxygen saturation ( $\mathrm{SpO} 2)$ was started and baseline values were recorded. One group received $40 \mathrm{mg} / \mathrm{kg}$ body weight of magnesium sulphate in $10 \mathrm{ml}$ of isotonic $0.9 \%$ saline slowly over ten minutes under monitoring and was completed approximately 1.5 minutes before the induction of anaesthesia. The other group was not pretreated with Magnesium Sulphate before the induction of anaesthesia. The person who injected the drug and observed for fasciculations and post-operative myalgia was blinded. General anesthesia was induced with Fentanyl $1.5 \mu \mathrm{g} / \mathrm{kg}$, IV propofol 2.0$2.5 \mathrm{mg} / \mathrm{kg}$ followed by succinylcholine $2 \mathrm{mg} / \mathrm{kg}$ to facilitate orotracheal intubation. The trachea was intubated with a cuffed orotracheal tube of appropriate size. Anesthesia was maintained with $60 \%$ N2O in oxygen with $0.5-1 \%$ isoflurane. Intermittent boluses of Atracurium bromide were used to achieve muscle relaxation. Minute ventilation was adjusted to maintain normocapnia (end tidal carbon-dioxide [EtCO2] between 34 and $38 \mathrm{~mm} \mathrm{Hg}$ ) and $\mathrm{EtCO} 2$ was monitored. In case of any adverse side effects, the drug administration was stopped and replaced with calcium gluconate. The neuro-muscular blockade was antagonized with neostigmine $0.05 \mathrm{mg} / \mathrm{kg}$ and glycopyrrolate $0.01 \mathrm{mg} / \mathrm{kg}$ and trachea was extubated. All patients stayed in PACU for $24 \mathrm{~h}$ after the end of surgery.

\section{Patients and grouping}

Patients were randomly allocated to one of the groups using table of randomization. Each group consists of 50 patients. Groups were as follows:

\section{Group M (Magnesium sulphate Group)}

Received $40 \mathrm{mg} / \mathrm{kg}$ magnesium sulphate in 10 $\mathrm{ml}$ of isotonic $0.9 \%$ saline slowly over ten minutes under monitoring which was completed approximately 1.5 minutes before the induction of anaesthesia.

\section{Group S (No magnesium sulphate given)}

Patients did not receive magnesium sulphate before the induction of anaesthesia. Study drugs were prepared by an Anesthesiologist who was not involved in the study. Anesthesiologist who observed the patient and surgeon were unaware of the study group until the end of the study.

Fasciculations were measured immediately after the administration of Succinylcholine and graded as follows by a four point scale given by Foster (1960).

1) No visible fasciculations will be termed Nil and scored 0

2) Very fine in fingertip, neck, face or fingertip movements, Mild and 1

3) Obvious muscle twitching at more than one site or movement of limbs, Moderate and 2

4) Vigorous, sustained and widespread fasciculations, Severe and 3

Post-operative myalgia was observed within 24 hours after the surgery by a four point scale given by White (1962) and recorded as

0 - No muscle pain

1 - Mild (muscle stiffness or pain on one area only but no treatment required)

2 - Moderate (muscle pain or stiffness indicated by the patient himself and treatment required)

3 - Severe (generalized, severe pain requiring more treatment).

\section{STATISTICAL ANALYSIS}

A total sample size of 100 patients $(n=50)$ for each group was calculated using PASSE (power and sample estimation) for study design and analysis. 
To obtain a 100 study sample size and design, a total of 120 patients were included in which 20 patients were excluded on the basis of study design and exclusion criteria.

Statistical analysis was performed using Microsoft (MS) Office Excel Software (Microsoft Microsoft Excel, Redmond, Washington: Microsoft 2003, Computer software). Results were expressed as mean \pm standard deviation, number and percentage $(\%)$. Data were analyzed using post hoc analysis method. Normally distributed data were assessed using unpaired Student's $t$-test (for comparison of parameters among groups). Comparison was carried out using Chi-square test with a $P$ value reported at $95 \%$ confidence level. Level of significance used was $P=0.05$.

\section{RESULTS}

Demographic data of two groups of patients as shown in table 1 were without significant difference. The Overall incidence of fasciculation was 06(12\%) patients in group $\mathrm{M}$ and $43(86 \%)$ patients in group $\mathrm{S}$. The incidence of fasciculation between two groups was highly significant $(\mathrm{p}=0.001)$ table 2 and postoperative myalgia was present in $9(18 \%)$ patients of Group $\mathrm{M}$ and $38(76 \%)$ patients in Group S experienced myalgia in postoperative period. The results were highly significant between two groups $(\mathrm{p}=0.001)$ table2 .

Table-1: Demographic data of patients

\begin{tabular}{|l|l|l|l|}
\hline Variables & $\begin{array}{l}\text { Group M } \\
\mathbf{N = 5 0}\end{array}$ & $\begin{array}{l}\text { GROUP S } \\
\text { N=50 }\end{array}$ & P VALUE \\
\hline Age (years) & $35.55 \pm 13.56$ & $32.80 \pm 13.37$ & 0.85 \\
\hline Sex $(\mathrm{M} / \mathrm{F})$ & $29 / 21$ & $28 / 22$ & 1.0 \\
\hline Weight $(\mathrm{kg})$ & $61.50 \pm 8.87$ & $62.50 \pm 10.99$ & 0.82 \\
\hline Height $(\mathrm{cm})$ & $166.3 \pm 4.6$ & $168.4 \pm 5.5$ & 0.264 \\
\hline ASA class $(\mathrm{I} / \mathrm{II})$ & $32 / 18$ & $35 / 15$ & 0.431 \\
\hline
\end{tabular}

Comparison of sex and ASA distribution between the two groups was evaluated using Chi-square test. ASA: American Society of Anaesthesiologists.

Table-2: Comparison of outcome variables between the two groups

\begin{tabular}{|l|l|l|l|}
\hline Incidence of fasciculation & Group M & Group S & P value \\
\hline Grade 0 & $92.28 \%$ & $14 \%$ & $\mathbf{0 . 0 0 4}$ \\
\hline Grade 1 & $12 \%$ & $22 \%$ & $\mathbf{0 . 0 0 3}$ \\
\hline Grade 2 & $\mathbf{0 \%}$ & $38 \%$ & $\mathbf{0 . 0 0 1}$ \\
\hline Grade 3 & $\mathbf{0 \%}$ & $26 \%$ & $\mathbf{0 . 0 0 2}$ \\
\hline Incidence of post-operative myalgia & & & \\
\hline Grade 0 & $56 \%$ & $8 \%$ & $\mathbf{0 . 0 0 4}$ \\
\hline Grade 1 & $10 \%$ & $28 \%$ & $\mathbf{0 . 0 0 5}$ \\
\hline Grade 2 & $8 \%$ & $50 \%$ & $\mathbf{0 . 0 0 4}$ \\
\hline Grade 3 & $0 \%$ & $14 \%$ & $\mathbf{0 . 0 0 1}$ \\
\hline
\end{tabular}

Comparison of quantitative variable and fasciculation grade between the two groups was evaluated using MannWhitney U test.

\section{DISCUSSION}

Succinylcholine, a depolarizing muscle relaxant was introduced in 1952 by Sleff and Foldes and has a unique place in clinical practice because it causes quick and excellent skeletal muscle relaxation for few minutes followed by spontaneous recovery. It possesses a unique property of rapid onset and short duration of action, but is accompanied by side effects like muscular fasciculations, myalgias, masseter spasm, hyperkalaemia and rhabdomyolysis. It also increases intracranial pressure, intraocular pressure and intragastric pressure [15]. The pathophysiology of fasciculations is unclear, but it may be induced by axonal depolarization caused by connection between succinylcholine and presynaptic and cholinergic nicotinic receptors. ${ }^{16}$ Muscle fasciculations and subsequent postoperative myalgia associated with the use of Suxamethonium is a common clinical problem and a major distressing factor for the patient. Many attempts have been made to avoid these undesirable effects, which include pretreatment with Rocuronium, Lignocaine, Gallamine, Vecuronium and Magnesium Sulphate[17].

Present study was done to evaluate the role of Magnesium Sulphate in attenuating Succinylcholine induced muscle fasiculations and post-operative myalgia. In our observational study, we evaluated two groups of patients having similar baseline characteristics, one group received Magnesium Sulphate pretreatment (group M) $40 \mathrm{mg} / \mathrm{kg}$ body weight before induction of anesthesia while the other group of 
patients did not receive Magnesium Sulphate (Group S).

Our results were similar to a study by Aldrete, Zahler et al. [18] to evaluate the effect of a combination of Magnesium Sulfate with Propofol for induction of anesthesia on Succinylcholine induced fasciculations and myalgia. This study was done on 60 adult patients undergoing surgery under general anesthesia. Patients were divided into two equal groups. The patients of MG Group were pretreated with Magnesium Sulfate 40 $\mathrm{mg} / \mathrm{kg}$ body weight, while patients of NS group were given isotonic saline $0.9 \%$ intravenously. Anesthesia was induced with Fentanyl $1.5 \mathrm{mcg} / \mathrm{kg}$ and propofol 2 $\mathrm{mg} / \mathrm{kg}$, followed by administration of succinylcholine 2 $\mathrm{mg} / \mathrm{kg}$ intravenously. It was found that $50 \%$ of the subjects who had received Magnesium Sulphate did not experience fasciculations, while in placebo group all patients experienced fasciculations. Another study was done by Ahsan B, Rahimi E et al. [19] al in 2012 to investigate the effects of Magnesium Sulphate on Succinylcholine induced fasciculations during the induction of general anaesthesia. It was done on a hundred patients, who were candidates for surgery under general anaesthesia. Patients were selected and divided into two equal groups of cases and controls.

The cases received magnesium sulphate, while the controls received normal saline. The result of their study is similar to our study which found that there was significant difference between the two groups of patients in terms of the degree of fasciculation and myalgia .The difference between our studies was that while they had a control group which received normal saline, in our study, we had two groups one of which received magnesium sulphate pretreatment while the other did not.

Another study by Sakuraba S et al. in [20] 2006 which has similar results to our study was done with the aim to evaluate the effects of pretreatment with Magnesium Sulphate as compared to precurarization with vecuronium, on Succinylcholine induced muscle fasiculations and subsequent tracheal intubation induced hemodynamic changes during rapid sequence induction. Their study compared magnesium sulphate with vecuronium and normal saline, having three groups in total, while in our study; we had only two groups of patients, in which one group was pretreated with magnesium sulphate while the other group was not. Another study by Laurence AS[21] in 1987 also showed that magnesium sulphate is useful both for reducing fasciculation during induction of anaesthesia. In their study, $33 \%$ of the magnesium sulphate group did not experience fasciculations at all.

In our study no patient showed any clinical signs of hypermagnesemia. Many studies have shown the use of Magnesium Sulfate in the dose of 40-60 $\mathrm{mg} / \mathrm{kg}$ without any sign of hypermagnesemia or clinically significant rise in serum magnesium levels after infusion of Magnesium Sulfate for many hours. Tauzin-Fin et al.[22] used Magnesium Sulfate 50 $\mathrm{mg} / \mathrm{kg}$ over a period of $20 \mathrm{~min}$ preoperatively without any rise in serum Magnesium level.

Tramer et al.[23] estimated serum Magnesium level after giving a bolus of $3 \mathrm{~g}(20 \% 15 \mathrm{ml})$ followed by a continuous infusion of $500 \mathrm{mg} / \mathrm{h}$ for $20 \mathrm{~h}$ (total amount of magnesium: $13 \mathrm{~g}$ ). In their study, before treatment with Magnesium Sulphate,serum Magnesium level was $0.74 \pm 0.09 \mathrm{mmol} / \mathrm{l}$, while after infusion for $20 \mathrm{~h}$ it was $1.34 \pm 0.09 \mathrm{mmol} / \mathrm{l}$ (levels were not high enough to produce clinical effects of hypermagnesemia).

In presence of normal renal functions, renal elimination of Magnesium is rapid. Ryu et al. [24] injected Magnesium Sulfate $50 \mathrm{mg} / \mathrm{kg}$ IV as bolus and then $15 \mathrm{mg} / \mathrm{kg} / \mathrm{hr}$ IV infusion till the end of surgery. Serum magnesium levels were found to be significantly higher in patients who received Magnesium Sulfate than those who received saline only $(1.5 \pm 0.2$ vs. $0.9 \pm$ $0.1 \mathrm{mmol} / \mathrm{l})$. Magnesium toxicity begins at the concentration of $2.5-5 \mathrm{mmol} / \mathrm{l}$, which is much higher than highest level observed in their study [25]. When serum magnesium level reaches $3.1 \mathrm{mmol} / \mathrm{l}$, depression of deep tendon reflexes occurs as a sign of toxicity [26]. We used $40 \mathrm{mg} / \mathrm{kg}$ body weight of Magnesium Sulphate in $10 \mathrm{ml}$ of isotonic $0.9 \%$ saline slowly over ten minutes under monitoring. It was started before anaesthesia and was completed approximately 1.5 minutes before the induction of anaesthesia. The other group did not receive Magnesium Sulphate before the induction of anaesthesia. This is a safe dose, considering the result of above studies and no patient had any sign of magnesium toxicity or any particular side effects in the administered dose and it was found to be safe[27].

Therefore, we reach to the conclusion that Magnesium Sulphate can greatly attenuate Succinylchoine induced muscle fasciculation as well as the post-operative myalgia. Magnesium Sulphate is a safe drug having a high therapeutic index. It also has been listed in the WHO list of most essential drugs and is available easily as well as is very economical to use. Other drugs e.g. Rocuronium,Vecuronium, Lignocaine have also been used for prevention of post anaesthesia fasciculations, but these drugs may not be available in certain countries or may be very expensive[28-30].

\section{REFERENCES}
1. Hewer,
C.
L."
thestagesandsignsofgeneralanaesthesia". BMJ. 2(3996):274276. doi:10.1136/bmj.2.3996.274. PMC 2087073. PMID 20780832. 
2. Bourne, J.G, Collier, H.O.J. (1952). Somers GF. Succinylcholine (succinoylcholine): musclerelaxant of short action. Lancet, 1: 1225 \pm 9 .

3. Churchill-Davidson, H. C. (1954). Suxamethonium (succinylcholine) chloride and muscle pains. British Medical Journal, 1(4853), 74.

4. Crawford, J. S. (1971). Suxamethonium muscle pains and pregnancy. BJA: British Journal of Anaesthesia, 43(7), 677-680.

5. Ali, A. H. (1989). Neuromuscular block and its antagonism: Clinical aspects. General Anaesthesia, 5th edn. London: Butterworths, 164-84.

6. Yun, M. J., Kim, Y. H., Go, Y. K., Shin, J. E., Ryu, C. G., Kim, W., ... \& Jung, W. S. (2010). Remifentanil attenuates muscle fasciculations by succinylcholine. Yonsei medical journal,51(4), 585-589.

7. James, M. F., Cork, R. C., \& Dennett, J. E. (1986). Succinylcholine pretreatment with magnesium sulfate. Anesthesia and analgesia, 65(4), 373-376.

8. Schreiber, J. U., Lysakowski, C., Fuchs-Buder, T., \& Tramer, M. R. (2005). Prevention of succinylcholine-induced fasciculation and myalgiaa meta-analysis of randomized trials. Anesthesiology: The Journal of the American Society of Anesthesiologists, 103(4), 877-884.

9. Shin, Y. H., Choi, S. J., Jeong, H. Y., \& Kim, M. H. (2011). Evaluation of dose effects of magnesium sulfate on rocuronium injection pain and hemodynamic changes by laryngoscopy and endotracheal intubation. Korean journal of anesthesiology, 60(5), 329.

10. Mahendra, M., \& Nalin, T. (2012). Effect of magnesium sulphate with propofol induction of anesthesia on Sch insuced muscle fasiculations and myalgia. J Anesthesiol Clin Pharmacol, 28(1), 8185.

11. Lysakowski, C., Dumont, L., Czarnetzki, C., \& Tramèr, M. R. (2007). Magnesium as an adjuvant to postoperative analgesia: a systematic review of randomized trials. Anesthesia \& Analgesia, 104(6), 1532-1539.

12. Kararmaz, A., Kaya, S., Turhanoglu, S., \& Ozyilmaz, M. A. (2003). Effects of high-dose propofol on succinylcholine-induced fasciculations and myalgia. Acta anaesthesiologica scandinavica, 47(2), 180-184.

13. Shoroghi, M., Zahedi, H., Farahbakhsh, F., Sheikhvatan, M., \& Abbasi, A. (2009). The effect of thiopentone on severity and duration of succinylcholine-induced fasciculation. Clinical neuropharmacology, 32(2), 94-96.

14. Lysakowski, C., Dumont, L., Czarnetzki, C., \& Tramèr, M. R. (2007). Magnesium as an adjuvant to postoperative analgesia: a systematic review of randomized trials. Anesthesia \& Analgesia, 104(6), 1532-1539.

15. Parmar, S., Vyas, A., \& Sheikh, A. (2013). Usefulness of propofol to prevent succinylcholine induced fasciculations and myalgia, a comparison with thiopentone sodium as an induction agent. Int J Med Sci Public Health, 2, 339-43.

16. Maddineni, V. R., Mirakhur, R. K., \& Cooper, A. R. (1993). Myalgia and biochemical changes following suxamethonium after induction of anaesthesia with thiopentone or propofol. Anaesthesia, 48(7), 626-628.

17. Garg, K., Luthra, N., Sud, S., \& Kaul, T. K. (2014). Effect of repeat bolus dose of propofol on succinylcholine-induced fasciculations and myalgia. Journal of Mahatma Gandhi Institute of Medical Sciences, 19(2), 106.

18. Aldbete, J. A., Zahler, A., \& Aikawa, J. K. (1970). Prevention of succinylcholine-induced hyperkalaemia by magnesium sulfate. Canadian Anaesthetists' Society Journal, 17(5), 477-484.

19. Ahsan, B., Rahimi, E., Moradi, A., \& Rashadmanesh, N. (2014). The effects of magnesium sulphate on succinylcholine-induced fasciculation during induction of general anaesthesia. J. Pak. Med. Assoc, 64, 1151-1153.

20. Sakuraba, S., Serita, R., Kosugi, S., Eriksson, L. I., Lindahl, S. G. E., \& Takeda, J. (2007). Pretreatment with magnesium sulphate is associated with less succinylcholine-induced fasciculation and subsequent tracheal intubationinduced hemodynamic changes than precurarization with vecuronium during rapid sequence induction. Acta Ancesthesiologica Belgica, 57(3), 253.

21. Laurence, A. S. (1987). Myalgia and biochemical changes following intermittent suxamethonium administration: Effects of alcuronium, lignocaine, midazolam and suxamethonium pretreatments on serum myoglobin, creatinine kinase and myalgia. Anaesthesia, 42(5), 503-510.

22. Tauzin-Fin, P., Sesay, M., Delort-Laval, S., KrolHoudek, M. C., \& Maurette, P. (2006). Intravenous magnesium sulphate decreases postoperative tramadol requirement after radical prostatectomy. European journal of anaesthesiology, 23(12), 1055-1059.

23. Tramer, M. R., Schneider, J., Marti, R. A., \& Rifat, K. (1996). Role of magnesium sulfate in postoperative analgesia. Anesthesiology: The Journal of the American Society of Anesthesiologists, 84(2), 340-347.

24. Ryu, J. H., Kang, M. H., Park, K. S., \& Do, S. H. (2008). Effects of magnesium sulphate on intraoperative anaesthetic requirements and postoperative analgesia in gynaecology patients receiving total intravenous anaesthesia. British journal of anaesthesia, 100(3), 397-403.

25. Wacker, W. E., \& Parisi, A. F. (1968). Magnesium metabolism. New England Journal of Medicine, 278(14), 772-776. 
26. Muirhead, N., Catto, G.R.(1986). Aids to fluid and electrolyte balance. Philadelphia: Churchill Livingstone. 1986: 88.

27. Han, J. U. (2012). About uses of magnesium during perioperative period. Korean journal of anesthesiology, 62(6), 509.

28. Wong, S. F., \& Chung, F. (2000). Succinylcholineassociated myalgia. Anaesthesia, 55(2), 144-152.
29. James, M. F., Cork, R. C., \& Dennett, J. E. (1986). Succinylcholine pretreatment with magnesium sulfate. Anesthesia and analgesia, 65(4), 373-376.

30. Schreiber, J. U., Lysakowski, C., Fuchs-Buder, T., \& Tramer, M. R. (2005). Prevention of succinylcholine-induced fasciculation and myalgiaa meta-analysis of randomized trials. Anesthesiology: The Journal of the American Society of Anesthesiologists, 103(4), 877-884. 